\title{
Frequency, Expected Effects, Obstacles, and Facilitators of Disclosure of Patient Safety Incidents: A Systematic Review
}

\author{
Minsu Ock ${ }^{1 *}$, So Yun Lim* ${ }^{2 * *}$, Min-Woo Jo' ${ }^{1}$, Sang-il Lee ${ }^{1}$ \\ ${ }^{1}$ Department of Preventive Medicine, University of Ulsan College of Medicine, Seoul; ${ }^{2}$ Department of Medicine, University of Ulsan College of \\ Medicine, Seoul, Korea
}

Objectives: We performed a systematic review to assess and aggregate the available evidence on the frequency, expected effects, obstacles, and facilitators of disclosure of patient safety incidents (DPSI).

Methods: We used the Preferred Reporting Items for Systematic Reviews and Meta-Analyses (PRISMA) guidelines for this systematic review and searched PubMed, Scopus, and the Cochrane Library for English articles published between 1990 and 2014. Two authors independently conducted the title screening and abstract review. Ninety-nine articles were selected for full-text reviews. One author extracted the data and another verified them.

Results: There was considerable variation in the reported frequency of DPSI among medical professionals. The main expected effects of DPSI were decreased intention of the general public to file medical lawsuits and punish medical professionals, increased credibility of medical professionals, increased intention of patients to revisit and recommend physicians or hospitals, higher ratings of quality of care, and alleviation of feelings of guilt among medical professionals. The obstacles to DPSI were fear of medical lawsuits and punishment, fear of a damaged professional reputation among colleagues and patients, diminished patient trust, the complexity of the situation, and the absence of a patient safety culture. However, the factors facilitating DPSI included the creation of a safe environment for reporting patient safety incidents, as well as guidelines and education for DPSI.

Conclusions: The reported frequency of the experience of the general public with DPSI was somewhat lower than the reported frequency of DPSI among medical professionals. Although we identified various expected effects of DPSI, more empirical evidence from real cases is required.

Key words: Patient safety, Medical errors, Disclosure of patient safety incidents, Systematic review

Received: November 2, 2016 Accepted: January 17, 2017

Corresponding author: Sang-il Lee, MD, PhD

88 Olympic-ro 43-gil, Songpa-gu, Seoul 05505, Korea

Tel: +82-2-3010-4284, Fax: +82-2-477-2898

E-mail: sleemd@amc.seoul.kr

${ }^{*}$ Current affiliation: Department of Preventive Medicine, Ulsan University Hospital, University of Ulsan College of Medicine, Ulsan, Korea.

${ }^{* *}$ Current affiliation: Asan Medical Center, Seoul, Korea.

This is an Open Access article distributed under the terms of the Creative Commons Attribution Non-Commercial License (http://creativecommons.org/licenses/by$\mathrm{nc} / 4.0 /$ ) which permits unrestricted non-commercial use, distribution, and reproduction in any medium, provided the original work is properly cited.

\section{INTRODUCTION}

To improve patient safety, knowledge of the scale of patient safety incidents and the prevention thereof is important, but the response to patient safety incidents that have already occurred is also valuable [1]. The response to patient safety incidents encompasses how they are dealt with and how their damage can be minimized. When faced with patient safety incidents, which include adverse events, no-harm incidents, and near misses [2], patients wonder what happened, and they have a right to know about the incident [3]. Furthermore, 
medical professionals, particularly physicians, have a responsibility to inform patients about patient safety incidents [4]. Thus, disclosure of patient safety incidents (DPSI) is necessary when patient safety incidents occur.

DPSI does not just refer to informing patients about the incident. The definition of DPSI varies among researchers, but DPSI typically includes "an acknowledgment; an expression of regret or an apology; an investigation into the incident; providing a factual explanation of what happened and explaining the steps being taken to manage the incident and prevent recurrence" $[5,6]$. In the present study, we defined DPSI as follows: when a patient safety incident occurs, medical professionals preemptively explain the incident to the patients and their caregivers, express sympathy and regret for the incident, deliver an apology and compensation appropriately if needed, and promise to prevent its recurrence.

Various researchers and institutions have highlighted the importance of DPSI in terms of patient safety. For example, DPSI is regarded as a significant issue affecting patient engagement and involvement, which is one of the 10 key patient safety domains [7]. The National Quality Forum adopted DPSI as one of its 34 safe practices required for patient safety [8]. Furthermore, the accreditation standards of the Accreditation Canada demand that healthcare institutions conduct DPSI [9].

However, published experiences with the implementation of DPSI in practice are limited to some Western countries $[5,10]$. Furthermore, many healthcare professionals have a number of concerns about the risks of DPSI $[10,11]$. In order to expand and deepen the discussion on DPSI, an accurate understanding and synthesis of the evidence on DPSI would be helpful. Although several articles have reviewed the literature related to DPSI $[10,11]$, no studies have used the systematic review (SR) method to do so, to the best of our knowledge. Therefore, in this present study, we conducted a SR to assess and aggregate the evidence on the frequency, expected effects, obstacles, and facilitators of DPSI.

\section{METHODS}

\section{Key Questions}

We applied the PRISMA (Preferred Reporting Items for Systematic Reviews and Meta-Analyses) guidelines to this SR [12]. The following key questions were specified:

1. How often does DPSI happen?

1-1. How often do medical professionals conduct DPSI?
1-2. How often does the general public experience DPSI?

2. What expected effects does DPSI have on medical professionals and the general public?

3. What factors influence DPSI?

3-1. What are the obstacles to DPSI?

3-2. What are the facilitators of DPSI?

\section{Organization of the Systematic Review Team}

The SR team had four members. Three of the team members were physicians who had experience with research into patient safety and SRs. The other was a medical student who had participated in health services research on several occasions.

\section{Search}

We searched for English articles published between 1990 and 2014 using PubMed, Scopus, and the Cochrane Library. The search date was March 13, 2015. We combined terms related to DPSI, such as "disclosure," "sorry," "apology," and "duty of candor." The search strategy is specified in Supplemental Table 1 . The search was restricted to title and abstract. We did not carry out additional searches for gray literature.

\section{Eligibility and Article Selection}

Articles were eligible for inclusion if they contained empirical evidence from qualitative or quantitative analyses of the frequency, expected effects, obstacles, and facilitators of DPSI. Review articles were excluded. Two authors (MO and SYL) independently conducted the title screening and abstract review. If there were disagreements and the two authors could not reach a resolution, a third author (SIL) was consulted.

\section{Data Extraction and Quality Assessment}

Data extraction was sequentially conducted. One author (MO) first extracted the data and another author (SYL) verified the results by comparing the extracted data and original articles. We did not assess the quality of the articles, including risk of bias, due to variations in the methodology of the included articles.

\section{RESULTS}

\section{Article Selection and Characteristics}

A total of 99 articles were selected for full-text reviews from 4380 articles identified by a database search (Supplemental Table 2). Figure 1 details the article selection process. Approximately half of the articles for the full-text reviews $(n=53$, 


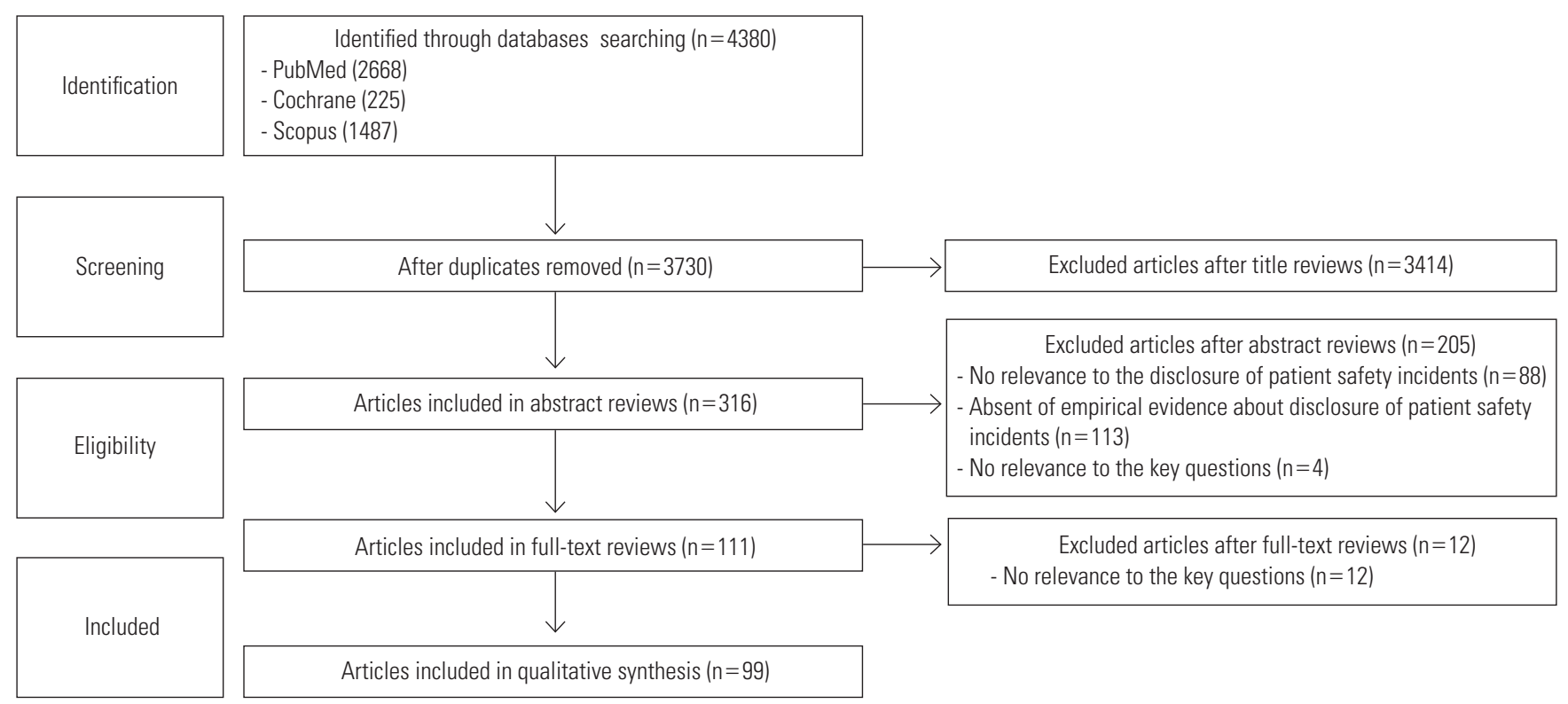

Figure 1. Flow chart of article selection.

Table 1. Key findings on the frequency of and experiences with disclosure of patient safety incidents

\begin{tabular}{|c|c|c|}
\hline & Medical professionals & The general public \\
\hline $\begin{array}{l}\text { Actual frequency } \\
\text { or experience }\end{array}$ & $\begin{array}{l}\text { There was considerable variation in the reported frequency of } \\
\text { medical professionals' disclosure of patient safety incidents [13-16] } \\
\text { Disclosure of patient safety incidents was conducted more often } \\
\text { for minor errors than major errors [17,18] } \\
\text { Physicians tended to disclose patient safety incidents more } \\
\text { frequently than other medical professionals [19] }\end{array}$ & $\begin{array}{l}\text { The general public reported less experience with the disclosure } \\
\text { of patient safety incidents than the reported frequency of medical } \\
\text { professionals' disclosure of patient safety incidents [33,34] } \\
\text { Most of the general public had little experience with full disclosure, } \\
\text { and medical professionals' disclosures were insufficient to meet the } \\
\text { needs and expectations of the public [35,36] }\end{array}$ \\
\hline $\begin{array}{l}\text { Intentions or } \\
\text { preferences in } \\
\text { hypothetical cases }\end{array}$ & $\begin{array}{l}\text { Contrary to the actual frequency of the disclosure of patient safety } \\
\text { incidents, in hypothetical cases, the intention to disclose patient } \\
\text { safety incidents generally increased with increased severity of the } \\
\text { disability caused by the medical error [17,20] } \\
\text { The intention to disclose patient safety incidents also increased } \\
\text { with increased clarity of the medical error in hypothetical cases [21-23] } \\
\text { Medical professionals were prone to conduct partial disclosure } \\
\text { rather than full disclosure [24,25] }\end{array}$ & $\begin{array}{l}\text { Most of the general public absolutely advocated for the disclosure } \\
\text { of patient safety incidents in all types of hypothetical cases }[25,37]\end{array}$ \\
\hline $\begin{array}{l}\text { Simple intentions } \\
\text { or preferences }\end{array}$ & $\begin{array}{l}\text { Most medical professionals expressed a simple intention to conduct } \\
\text { disclosure of patient safety incidents, and the numbers have gradually } \\
\text { grown in recent years }[23,26,27] \\
\text { Most medical professionals thought that disclosure of patient safet } \\
\text { incidents was unnecessary in the case of near misses }[17,22,28-32]\end{array}$ & $\begin{array}{l}\text { Most of the general public completely supported the disclosure of } \\
\text { patient safety incidents regardless of the type of incident [38-43] } \\
\text { Most of the general public thought that disclosure of patient safety } \\
\text { incidents was necessary in the case of near misses [38,41-43] }\end{array}$ \\
\hline
\end{tabular}

53.5\%) were published from 2010 onward. Of the 99 articles, 75 provided information on the frequency of DPSI (key question 1), 33 articles included the expected effects of DPSI (key question 2), and 20 articles described the obstacles to and facilitators of DPSI (key question 3).

\section{Key question 1-1: the frequency of disclosure of patient safety incidents among medical professionals}

Table 1 summarizes the key findings on the frequency of DPSI among medical professionals. The findings were divided as follows: actual frequency, intentions in hypothetical cases, and simple intentions.

First, in terms of actual frequency, considerable variation was found in the reported frequency of DPSI among medical professionals [13-16]. Medau et al. [13] reported that 26 out of 30 psychotherapists (86.7\%) adopted the practice of disclosing their errors, but Lander et al. [14] found that just 20 out of 210 otolaryngologists $(9.4 \%)$ reported that they disclosed errors and adverse events to patients. In particular, the estimated frequency using retrospective reviews of medication error 
reports and medical records was very low $[15,16]$. Furthermore, the reported frequency of DPSI among medical professionals was influenced by the severity of harm caused by the medical error. DPSI was conducted more often in the case of minor errors than major errors $[17,18]$. Kaldjian et al. [17] reported that $41 \%$ of faculty and residents had actually disclosed minor errors, but only $5 \%$ had disclosed major errors. Regarding differences among medical professionals, it seemed that physicians tended to perform DPSI more frequently than other medical professionals. Hobgood et al. [19] reported that the disclosure rates of physicians were significantly higher than those of nurses and out-of-hospital personnel.

Contrary to the actual frequency of DPSI, in hypothetical cases, the intention to conduct DPSI generally increased with the severity of the disability caused by the medical error $[17,20]$. The intention to conduct DPSI also increased with the clarity of the medical error in hypothetical cases [21-23]. White et al. [23] reported that trainees' disclosure intentions were significantly higher for more apparent errors than for less apparent errors. Furthermore, medical professionals tended to conduct partial DPSI rather than full DPSI $[24,25]$. Chan et al. [24] determined that surgeons used the term "error" or "mistake" in 34 out of 60 cases (56.7\%), gave a verbal apology in 28 out of 60 cases (46.7\%), and told the patient about future precautions in only 5 out of 60 cases (8.3\%).

Most medical professionals expressed a simple intention to conduct DPSI $[23,26]$, and the numbers have gradually increased in recent years [27]. Sorokin et al. [27] reported that trainees surveyed in 2008 more often acknowledged the moral responsibility to disclose adverse events to patients than those who responded to the same questionnaire in 2003. However, there were differences in the intention to conduct DPSI according to the type of medical error, similarly to what was observed with regard to actual frequency and intentions in hypothetical cases. In particular, most medical professionals still thought that DPSI was unnecessary in the case of a near miss [17,22,28-32]. For example, Evans et al. [30] reported that $71.6 \%$ of radiation oncologists and trainees thought that near misses should not be disclosed, although $94.8 \%$ of them thought that serious medical errors should be disclosed.

\section{Key question 1-2: experiences of the general public with disclosure of patient safety incidents}

Table 1 shows the key findings regarding the experiences of the general public with DPSI. Similarly to the findings ob- served among medical professionals, the findings were divided as follows: actual experience, preferences in hypothetical cases, and simple preferences.

The reported frequency of experiences with DPSI among the general public was lower than the reported frequency of DPSI among medical professionals [33,34]. Lyu et al. [34] determined that $11.4 \%$ of patients ( 27 of 236 ) who reported patient harm received an apology from the clinician or medical organization. Furthermore, most of the general public had little experience with full disclosure [35]. They experienced DPSI without some of its essential elements. Consequently, medical professionals' DPSI was insufficient to meet their needs and expectations [36].

Most of the general public absolutely advocated for DPSI in all types of hypothetical cases $[25,37]$. Matlow et al. [37] reported that $99 \%$ of parents wanted to be told of adverse events with any real or potential harm. Furthermore, most of the general public also completely supported DPSI, regardless of the type of incident [38-43]. Mazor et al. [38] found that $98.8 \%$ of health plan members wanted to be informed about errors. In particular, most of the general public generally thought that DPSI is necessary in the case of a near miss [38, 41-43], with the exception of one report [40].

\section{Key question 2: expected effects of disclosure of patient safety incidents}

Table 2 summarizes the expected effects of DPSI. Above all, DPSI was expected to reduce the rate of medical lawsuits and related costs, although empirical evidence based on real observational data is limited. Only two articles used a 1-group pretest/post-test design [44,45]. Kachalia et al. [44] reported that, after full implementation of a disclosure program, the average monthly rate of newly made claims decreased from 7.03 to 4.52 per 100000 patient encounters, and the average monthly rate of lawsuits also declined from 2.13 to 0.75 per 100000 patient encounters. Adams et al. [45] determined that, after implementation of a disclosure program, the rate of gastroenterology-related claims per 1000 patient encounters declined from 0.160 to $0.068 \%$, and the mean total liability per gastroenterologyrelated claim also decreased from US dollar (USD) 167309 to USD 81107.

Several other articles also found that DPSI did not increase the likelihood of legal action from the general public [35,43,4649]. For example, Hobgood et al. [48] reported that $35 \%$ of patients were less likely to file a suit if they were informed of the 
Table 2. Major expected effects of disclosure of patient safety incidents

\begin{tabular}{ll}
\hline Area & \multicolumn{1}{c}{ Key findings } \\
\hline $\begin{array}{l}\text { Medical lawsuits } \\
\text { and punishment }\end{array}$ & $\begin{array}{l}\text { Although empirical evidence is limited, disclosure of patient safety incidents reduced the rate of medical lawsuits and related costs [44,45] } \\
\text { Disclosure of patient safety incidents did not increase the likelihood of legal action from the general public [35,43,46-49] } \\
\text { Disclosure of patient safety incidents decreased the intention of the general public to punish medical professionals [50] } \\
\text { Disclosure of patient safety incidents increased the intention of the general public to forgive medical professionals [42] }\end{array}$ \\
& $\begin{array}{l}\text { Disclosure of patient safety incidents helped to build a better physician-patient relationship, improved patient satisfaction, and generally } \\
\text { Patients } \\
\text { increased the credibility of medical professionals [18,35,38] }\end{array}$ \\
& $\begin{array}{l}\text { Disclosure of patient safety incidents increased patients' intention to revisit and recommend the physicians or hospitals [54,55] } \\
\text { Disclosure of patient safety incidents could improve patients' evaluation of the quality of care [54,56] }\end{array}$ \\
Medical professionals & Disclosure of patient safety incidents reduced medical professionals' feelings of guilt [17,20,29] \\
Others & Disclosure of patient safety incidents would decrease the risks of similar medical errors [52] \\
& Physicians who disclose patient safety incidents can be role models for medical students [57] \\
& Disclosure could affect relationships among medical professionals in a positive way [20]
\end{tabular}

error, and another $64 \%$ of patients were not affected by disclosure. Furthermore, DPSI decreased the intention of the general public to punish medical professionals [50] and increased the intention of the general public to forgive medical professionals [42]. Most medical professionals also agreed with the positive expected effects of DPSI on medical lawsuits and punishments $[14,18,31,51]$, although one article reported that a fair number of surgeons disagreed with these expected effects [52]. However, some articles found limited effects of DPSI on medical lawsuits and punishment $[38,53]$. Wu et al. [53] concluded that inclination to sue might not be influenced by DPSI on the basis of the results of a survey using video vignettes. In addition, Mazor et al. [38] determined that the reported likelihood of seeking legal advice may increase under some circumstances.

Various articles suggested several positive expected effects of DPSI in terms of patients. DPSI was expected to help build a better physician-patient relationship, improve patient satisfaction, and generally increase the credibility of medical professionals $[18,35,38]$. For example, only $13 \%$ of residents who disclosed serious errors considered that the disclosure negatively impacted their relationship with patients, and only $3 \%$ of interns and residents felt the same [18]. Furthermore, DPSI was expected to increase patients' intention to revisit and recommend the physicians or hospital $[54,55]$. In addition, DPSI was expected to improve patients' evaluation of quality of care $[54,56]$. However, one article showed that a considerable number of surgeons had negative opinions on these positive expected effects of DPSI, especially regarding the likelihood of patients to revisit the physician [52]. Some articles suggested that DPSI reduces medical professionals' feelings of guilt $[17,20,29]$. Gallagher et al. [29] reported that $74 \%$ of physicians who had conducted disclosure of a serious error experienced relief after the disclosure. Wagner et al. [20] also deter- mined that $86.1 \%$ of nurses who had been involved in the disclosure of a serious error were subsequently relieved.

DPSI was expected to decrease the risks of similar medical errors. Ghalandarpoorattar et al. [52] reported that $52.8 \%$ of surgeons agreed that DPSI reduced the risk of error recurrence. Furthermore, physicians who perform DPSI can be role models for medical students [57]. DPSI can also positively influence relationships among medical professionals. Of nurses who had been involved in the disclosure of a serious error, $43.9 \%$ thought that the DPSI positively affected the relationship between residents and nurses [20].

\section{Key question 3-1: obstacles to disclosure of patient safety incidents}

The obstacles to DPSI can be summarized in five main points (Table 3). First, despite the expected effects of DPSI on medical lawsuits and punishment, fear of medical lawsuits and punishment was the main factor affecting medical professionals' intention to perform DPSI [17,30,39]. According to the article by Evans et al. [30], 38.0\% of radiation oncologists and trainees thought that DPSI increased the likelihood of being sued, although 32.4\% felt that DPSI decreased the likelihood of being sued. However, according to the study of Dintzis et al. [28], only $11.2 \%$ of anatomic pathologists and laboratory medical directors thought that fear of being sued would influence their recommendations regarding DPSI.

Second, fear of a damaged professional reputation among colleagues and patients was frequently suggested as an obstacle to DPSI [17,32,52]. Various traits of medical professionals, such as shame and self-protection, could inhibit DPSI in this context [32].

Third, many medical professionals were afraid of undermining patient trust when they performed DPSI $[17,18,29,31,32,51$, 
Table 3. Obstacles to disclosure of patient safety incidents

\begin{tabular}{lc}
\hline Area & \multicolumn{1}{c}{ Key findings } \\
\hline Medical lawsuits and punishment & $\begin{array}{c}\text { Despite the expected effects of disclosure of patient safety incidents on medical lawsuits and punishment, } \\
\text { fear of medical lawsuits and punishment had a major effect on medical professionals' intentions to disclose } \\
\text { patient safety incidents [17,30,39] }\end{array}$ \\
$\begin{array}{l}\text { Fear of a damaged professional reputation among colleagues and patients was frequently suggested as an } \\
\text { obstacle to the disclosure of patient safety incidents [17,32,52] }\end{array}$ \\
$\begin{array}{l}\text { Many medical professionals were afraid of undermining patient trust when they performed disclosure of } \\
\text { patient safety incidents [17,18,29,31,32,51,52] }\end{array}$ \\
$\begin{array}{l}\text { Patients } \\
\text { The complexity of the situation when disclosing patient safety incidents could make medical professionals } \\
\text { patient safety incidents } \\
\text { Patient safety culture }\end{array}$ \\
$\begin{array}{c}\text { hesitant to disclose patient safety incidents [18 29,31,58] } \\
\text { The absence of a patient safety culture was mentioned as a reason for a failure to disclose patient safety } \\
\text { incidents [32,61] }\end{array}$
\end{tabular}

Table 4. Facilitators of disclosure of patient safety incidents

\begin{tabular}{lc}
\hline Area & Key findings \\
\hline Establishment of a patient safety culture & $\begin{array}{c}\text { Creation of a safe environment for reporting patient safety incidents facilitated the disclosure } \\
\text { of such incidents }[61,62]\end{array}$ \\
$\begin{array}{l}\text { Introduction of a policy for the disclosure of patient } \\
\text { safety incidents }\end{array}$ & $\begin{array}{c}\text { A framework and guidelines for the disclosure of patient safety incidents would help medical } \\
\text { professionals to disclose such incidents [64] }\end{array}$ \\
$\begin{array}{l}\text { Education and training on the disclosure of patient } \\
\text { safety incidents }\end{array}$ & $\begin{array}{c}\text { Education and training on the disclosure of patient safety incidents could enhance medical } \\
\text { professionals' ability and intention to disclose patient safety incidents [65-74]. }\end{array}$
\end{tabular}

52]. When medical professionals and patients were already in a complex situation, they thought that DPSI could worsen the situation and undermine patients' trust in medical professionals [32].

Fourth, the complexity of the situation when conducting DPSI could make medical professionals hesitant to disclose such incidents. If patients did not know about the occurrence of a medical error $[18,29,31]$, if patients did not seem to understand the explanation of the patient safety incidents $[18,29$, $31,58]$, or if patients seemed not to know what happened $[18,29,31]$, it was difficult for medical professionals to conduct DPSI. Cognitive impairments and cultural differences, including language, also made it harder to perform DPSI $[32,59]$. Furthermore, unfamiliarity with DPSI $[28,60]$ and busy schedules [32] were highlighted as barriers to DPSI.

Fifth, the absence of a patient safety culture was another reason for failing to conduct DPSI $[32,61]$.

\section{Key question 3-2: facilitators of disclosure of patient safety incidents}

The facilitators of DPSI can be summarized in three main points (Table 4). First, the creation of a safe environment for reporting patient safety incidents was found to facilitate DPSI $[61,62]$. Furthermore, a healthcare professional who observed another healthcare provider disclosing a medical error tended to be more likely to perform DPSI [63].
Second, a framework and guidelines for the DPSI would help medical professionals to undertake DPSI [64].

Third, education and training related to DPSI could enhance the ability and intention of medical staff to perform DPSI [6574]. For example, Gunderson et al. [69] determined that, after a DPSI educational module, medical students' confidence score regarding DPSI significantly improved and the number of medical students who included the essential elements of DPSI significantly increased. Furthermore, Coffey et al. [75] reported that all pediatric residents in their study were interested in obtaining education and training on DPSI.

\section{DISCUSSION}

We conducted a SR to assess and aggregate evidence on the frequency, expected effects, obstacles, and facilitators of DPSI. Although DPSI is an ethically important and inevitable issue in patient safety, no other SR has examined the topic.

\section{Frequency of Disclosure of Patient Safety Incidents}

Most importantly, the reported frequency of the experience of DPSI among the general public was somewhat lower than the frequency of DPSI reported by medical professionals $[33,34]$. Although differences in survey populations, wording, 
and time periods might help explain this discrepancy, this phenomenon could also be due to a perception gap between medical professionals and the general public regarding DPSI, especially its essential elements. Two studies supported this assumption. Mazor et al. [35] reported that patients emphasized key elements of DPSI, such as an apology, explanation, and promising to avoid its recurrence, but these essential elements were often missing. ledema et al. [36] also determined that the DPSI conducted by medical professionals rarely met the needs of most patients or their family members.

Furthermore, considerable variation was found in the reported frequency of medical professionals' DPSI [13-16]. This difference could be due to the methodological limitations of studies that mainly used self-administered surveys. According to studies of the frequency of the DPSI that used retrospective reviews of medication error reports and medical records, DPSI was rarely conducted $[15,16]$. These findings were similar to those regarding the underreporting of medical errors in a patient safety reporting system [76]. Studies that use self-administered questionnaire surveys can have a social desirability bias, so the reported frequency of DPSI among medical professionals might be overestimated.

Another distinctive feature in hypothetical cases was that the medical professionals' intention to conduct DPSI generally increased with the severity of the harm caused by the medical error and the clarity of the medical error $[20,52,63]$. Medical professionals' simple intention to conduct DPSI showed a similar tendency [18,28,29,31]. However, DPSI was generally found to be conducted more often for minor errors than major errors $[17,18]$. It seems that medical professionals find it more difficult to disclose major errors than minor errors. Therefore, it is necessary to develop systematic support to support DPSI, especially for major errors.

A discrepancy was also found in opinions regarding the disclosure of near misses between medical professionals and the general public. Most medical professionals felt that DPSI is unnecessary in the case of near misses [17,22,28-32], but most of the general public believed the opposite [77]. Hearing about the occurrence of a near miss could upset patients, but it would alert patients to the type of medical errors that they should be cautious about and would reassure them that the medical systems designed to keep them safe were working [39]. Further discussion on the necessity of disclosure of near misses will be required.

\section{Expected Effects of Disclosure of Patient Safety Incidents}

The main expected effects of DPSI were a decreased intention of the general public to file medical lawsuits and punish medical professionals, increased credibility of medical professionals, increased intention of patients to revisit and recommend physicians or hospitals, improved ratings of the quality of care, and alleviation of the guilty feelings of medical professionals. In general, both medical professionals and the general public agreed with these expected effects to a varying extent in studies. However, few studies have compared the outcomes of DPSI before and after the implementation of a DPSI program. In particular, only two articles reported a reduction in medical lawsuits and related costs $[44,45]$. More research evaluating the real effects of DPSI programs is needed to reach a definite conclusion on the expected effects of DPSI.

Among the various expected effects of the DPSI, there was a relatively large perception gap for the expected effects related to medical lawsuits and punishment between medical professionals and the general public. Although several studies reported that most medical professionals agreed with the positive expected effects of the DPSI on medical lawsuits and punishments $[14,18,31,51]$, a fair number of surgeons disagreed with them [52]. Furthermore, a study reported that the likelihood of seeking legal advice may increase under some circumstances [38]. More empirical evidence is needed to clarify this controversial issue.

Those medical professionals who acknowledged the positive expected effects of DPSI looked more favorably on the introduction of a DPSI program or policy at a hospital or national level. In particular, the finding that DPSI can reduce medical professionals' feelings of guilt would make medical professionals more likely to accept DPSI [20,29].

\section{Obstacles to and Facilitators of Disclosure of Patient Safety Incidents}

In this SR, the obstacles to DPSI were fear of medical lawsuits and punishment, fear of a loss of professional reputation among colleagues and patients, diminished patient trust when DPSI is performed, the complexity of the situation requiring DPSI, and the absence of a patient safety culture. Meanwhile, establishment of a patient safety culture, introduction of a DPSI policy, and development of education and training programs for DPSI were facilitators of DPSI. The most important point is 
that fear of medical lawsuits and punishment had a major effect on medical professionals' intention to perform DPSI, particularly in the case of major errors $[17,30,39]$, despite the expected effects of DPSI on medical lawsuits and punishment. One method that can dispel fears of being sued for malpractice is an apology law, in which a physician's apology is not considered an admission of fault [78]. However, more empirical evidence on the real effects of apology laws is required.

Another remarkable aspect is that the complexity of the situation requiring DPSI could make medical professionals hesitant to conduct DPSI. Considering medical professionals' lack of familiarity with DPSI $[28,60]$, the development and adoption of guidelines for DPSI [65] and education and training on DPSI [65-74] would help medical professionals to become more familiar with DPSI. These are also in line with the context of gaining traction on standardization of the care process in patient safety [79]. Furthermore, additional professional help, including risk management and language support, will be helpful.

Similar to the fact that creation of a patient safety culture encourages medical professionals to report in a patient safety reporting system, the creation of a patient safety culture also facilitates medical professionals' DPSI [62]. Although their reported objectives differ, DPSI and patient safety reporting systems are similar in that they aim to deliver the truth about patient safety incidents to other people [3]. Persistent effort is required to improve the patient safety culture in hospitals.

\section{Limitations}

Although the articles selected for full-text reviews were all included in peer-reviewed journals, we did not assess the quality of the articles, including the risk of bias. For this reason, we cannot exclude the possibility of a reporting or publication bias that might have meant that only articles reporting positive aspects of DPSI were included in this SR. Furthermore, we did not consider cultural context in this SR. Since most of the articles selected for full-text review were from Western countries, it could be argued that the articles mainly reflected the cultural context of Western countries. Further research in non-Western countries will be needed.

\section{CONCLUSION}

The reported frequency of the experience of DPSI among the general public was somewhat lower than the frequency of DPSI reported by medical professionals. In particular, it seemed that medical professionals' DPSI was insufficient to meet the needs and expectations of the general public, considering the fact that the general public experienced DPSI without some of its essential elements. Reducing the perception gap between the general public and medical professionals regarding DPSI will be required. Although we determined the various expected effects of DPSI, more empirical evidence from real cases is required. The results of this SR will aid in further investigations of DPSI.

\section{CONFLICT OF INTEREST}

The authors have no conflicts of interest associated with the material presented in this paper.

\section{ORCID}

Minsu Ock http://orcid.org/0000-0001-9949-9224

So Yun Lim http://orcid.org/0000-0002-5647-3718

Min-Woo Jo http://orcid.org/0000-0002-4574-1318

Sang-il Lee http://orcid.org/0000-0002-1068-7542

\section{REFERENCES}

1. Downie J, Lahey W, Ford D, Gibson E, Thomson M, Ward T, et al. Patient safety law: from silos to systems. Ottawa: Health Canada; 2006, p. 24-27.

2. World Health Organization. Conceptual framework for the international classification for patient safety: final technical report; 2009 [cited 2016 Aug 10]. Available from: http://www. who.int/patientsafety/taxonomy/icps_full_report.pdf.

3. Wolf ZR, Hughes RG. Error reporting and disclosure. In: Hughes $\mathrm{RG}$, editor. Patient safety and quality: an evidence-based handbook for nurses. Rockville: Agency for Healthcare Research and Quality; 2008, p. 8.

4. American Medical Association (AMA). The code says the AMA code of medical ethics' opinions on patient safety. AMA J Ethics 2011;13(9):626-628.

5. McLennan S, Beitat K, Lauterberg J, Vollmann J. Regulating open disclosure: a German perspective. Int J Qual Health Care 2012;24(1):23-27.

6. Disclosure Working Group. Canadian disclosure guidelines: being open and honest with patients and families; 2011 [cited 2017 Feb 15]. Available from: http://www.patientsafetyinstitute.ca/en/toolsResources/disclosure/Documents/CPSI\%20 
Canadian\%20Disclosure\%20Guidelines.pdf.

7. Wachter RM. Patient safety at ten: unmistakable progress, troubling gaps. Health Aff (Millwood) 2010;29(1):165-173.

8. National Quality Forum. Safe practices for better healthcare-2009 update: a consensus report; 2009 [cited 2017 Feb 15]. Available from: http://www.qualityforum.org/Publications/2009/03/Safe_Practices_for_Better_Healthcare\%E2\% 80\%932009_Update.aspx.

9. Accreditation Canada. Required organizational practices, handbook 2016 [cited 2016 Oct 10]. Available from: https://accreditation.ca/sites/default/files/rop-handbook-2016-en.pdf.

10. O'Connor E, Coates HM, Yardley IE, Wu AW. Disclosure of patient safety incidents: a comprehensive review. Int J Qual Health Care 2010;22(5):371-379.

11. Wu AW, Boyle DJ, Wallace G, Mazor KM. Disclosure of adverse events in the United States and Canada: an update, and a proposed framework for improvement. J Public Health Res 2013; 2(3):e32.

12. Moher D, Liberati A, Tetzlaff J, Altman DG; PRISMA Group. Preferred reporting items for systematic reviews and meta-analyses: the PRISMA statement. PLoS Med 2009;6(7):e1000097.

13. Medau I, Jox RJ, Reiter-Theil S. How psychotherapists handle treatment errors: an ethical analysis. BMC Med Ethics 2013;14: 50.

14. Lander LI, Connor JA, Shah RK, Kentala E, Healy GB, Roberson DW. Otolaryngologists' responses to errors and adverse events. Laryngoscope 2006;116(7):1114-1120.

15. Belela AS, Peterlini MA, Pedreira Mda L. Disclosure of medication error in a pediatric intensive care unit. Rev Bras Ter Intensiva 2010;22(3):257-263.

16. Lehmann LS, Puopolo AL, Shaykevich S, Brennan TA. latrogenic events resulting in intensive care admission: frequency, cause, and disclosure to patients and institutions. Am J Med 2005;118(4):409-413.

17. Kaldjian LC, Jones EW, Wu BJ, Forman-Hoffman VL, Levi BH, Rosenthal GE. Disclosing medical errors to patients: attitudes and practices of physicians and trainees. J Gen Intern Med 2007;22(7):988-996.

18. White AA, Gallagher TH, Krauss MJ, Garbutt J, Waterman AD, Dunagan WC, et al. The attitudes and experiences of trainees regarding disclosing medical errors to patients. Acad Med 2008;83(3):250-256.

19. Hobgood C, Xie J, Weiner B, Hooker J. Error identification, disclosure, and reporting: practice patterns of three emergency medicine provider types. Acad Emerg Med 2004;11(2):196-
199.

20. Wagner LM, Harkness K, Hébert PC, Gallagher TH. Nurses' disclosure of error scenarios in nursing homes. Nurs Outlook 2013;61(1):43-50.

21. Loren DJ, Klein EJ, Garbutt J, Krauss MJ, Fraser V, Dunagan WC, et al. Medical error disclosure among pediatricians: choosing carefully what we might say to parents. Arch Pediatr Adolesc Med 2008;162(10):922-927.

22. Loren DJ, Garbutt J, Dunagan WC, Bommarito KM, Ebers AG, Levinson W, et al. Risk managers, physicians, and disclosure of harmful medical errors. Jt Comm J Qual Patient Saf 2010;36 (3):101-108.

23. White AA, Bell SK, Krauss MJ, Garbutt J, Dunagan WC, Fraser VJ, et al. How trainees would disclose medical errors: educational implications for training programmes. Med Educ 2011; 45(4):372-380.

24. Chan DK, Gallagher TH, Reznick R, Levinson W. How surgeons disclose medical errors to patients: a study using standardized patients. Surgery 2005;138(5):851-858.

25. Espin S, Levinson W, Regehr G, Baker GR, Lingard L. Error or "act of God"? A study of patients' and operating room team members' perceptions of error definition, reporting, and disclosure. Surgery 2006;139(1):6-14.

26. Gallagher TH, Garbutt JM, Waterman AD, Flum DR, Larson EB, Waterman BM, et al. Choosing your words carefully: how physicians would disclose harmful medical errors to patients. Arch Intern Med 2006;166(15):1585-1593.

27. Sorokin R, Riggio JM, Moleski S, Sullivan J. Physicians-in-training attitudes on patient safety: 2003 to 2008. J Patient Saf 2011;7(3):133-138.

28. Dintzis SM, Stetsenko GY, Sitlani CM, Gronowski AM, Astion $\mathrm{ML}$, Gallagher TH. Communicating pathology and laboratory errors: anatomic pathologists' and laboratory medical directors' attitudes and experiences. Am J Clin Pathol 2011;135(5): 760-765.

29. Gallagher TH, Waterman AD, Garbutt JM, Kapp JM, Chan DK, Dunagan WC, et al. US and Canadian physicians' attitudes and experiences regarding disclosing errors to patients. Arch Intern Med 2006;166(15):1605-1611.

30. Evans SB, Yu JB, Chagpar A. How radiation oncologists would disclose errors: results of a survey of radiation oncologists and trainees. Int J Radiat Oncol Biol Phys 2012;84(2):e131-e137.

31. Garbutt J, Brownstein DR, Klein EJ, Waterman A, Krauss MJ, Marcuse EK, et al. Reporting and disclosing medical errors: pediatricians' attitudes and behaviors. Arch Pediatr Adolesc 
Med 2007;161(2):179-185.

32. McLennan SR, Diebold M, Rich LE, Elger BS. Nurses' perspectives regarding the disclosure of errors to patients: a qualitative study. Int J Nurs Stud 2016;54:16-22.

33. ledema R, Sorensen R, Manias E, Tuckett A, Piper D, Mallock N, et al. Patients' and family members' experiences of open disclosure following adverse events. Int I Qual Health Care 2008; 20(6):421-432.

34. Lyu HG, Cooper MA, Mayer-Blackwell B, Jiam N, Hechenbleikner EM, Wick EC, et al. Medical harm: patient perceptions and follow-up actions. J Patient Saf 2014. doi: https://doi.org/ 10.1097/PTS.0000000000000136.

35. Mazor KM, Greene SM, Roblin D, Lemay CA, Firneno CL, Calvi J, et al. More than words: patients' views on apology and disclosure when things go wrong in cancer care. Patient Educ Couns 2013;90(3):341-346.

36. ledema R, Allen S, Britton K, Piper D, Baker A, Grbich C, et al. Patients' and family members' views on how clinicians enact and how they should enact incident disclosure: the "100 patient stories" qualitative study. BMJ 2011;343:d4423.

37. Matlow AG, Moody L, Laxer R, Stevens P, Goia C, Friedman JN. Disclosure of medical error to parents and paediatric patients: assessment of parents' attitudes and influencing factors. Arch Dis Child 2010;95(4):286-290.

38. Mazor KM, Simon SR, Yood RA, Martinson BC, Gunter MJ, Reed GW, et al. Health plan members' views about disclosure of medical errors. Ann Intern Med 2004;140(6):409-418.

39. Moran GJ, Talan DA, Mower W, Newdow M, Ong S, Nakase JY, et al. Appropriateness of rabies postexposure prophylaxis treatment for animal exposures. Emergency ID Net Study Group. JAMA 2000;284(8):1001-1007.

40. Hammami MM, Attalah S, Al Qadire M. Which medical error to disclose to patients and by whom? Public preference and perceptions of norm and current practice. BMC Med Ethics 2010; 11:17.

41. Hingorani $M$, Wong $T$, Vafidis $G$. Attitudes after unintended injury during treatment a survey of doctors and patients. West J Med 1999;171(2):81-82.

42. Ushie BA, Salami KK, Jegede AS, Oyetunde M. Patients' knowledge and perceived reactions to medical errors in a tertiary health facility in Nigeria. Afr Health Sci 2013;13(3):820-828.

43. Witman AB, Park DM, Hardin SB. How do patients want physicians to handle mistakes? A survey of internal medicine patients in an academic setting. Arch Intern Med 1996;156(22): 2565-2569.
44. Kachalia A, Kaufman SR, Boothman R, Anderson S, Welch K, Saint $S$, et al. Liability claims and costs before and after implementation of a medical error disclosure program. Ann Intern Med 2010;153(4):213-221.

45. Adams MA, Elmunzer BJ, Scheiman JM. Effect of a health system's medical error disclosure program on gastroenterologyrelated claims rates and costs. Am J Gastroenterol 2014;109 (4):460-464.

46. Helmchen LA, Richards MR, McDonald TB. How does routine disclosure of medical error affect patients' propensity to sue and their assessment of provider quality? Evidence from survey data. Med Care 2010;48(11):955-961.

47. Hobgood C, Tamayo-Sarver JH, Elms A, Weiner B. Parental preferences for error disclosure, reporting, and legal action after medical error in the care of their children. Pediatrics 2005; 116(6):1276-1286.

48. Hobgood C, Tamayo-Sarver JH, Weiner B. Patient race/ethnicity, age, gender and education are not related to preference for or response to disclosure. Qual Saf Health Care 2008;17(1): 65-70.

49. Lester GW, Smith SG. Listening and talking to patients. A remedy for malpractice suits? West J Med 1993;158(3):268-272.

50. Schwappach DL, Koeck CM. What makes an error unacceptable? A factorial survey on the disclosure of medical errors. Int J Qual Health Care 2004;16(4):317-326.

51. Ogundiran TO, Adebamowo CA. Surgeon-patient information disclosure practices in southwestern Nigeria. Med Princ Pract 2012;21(3):238-243.

52. Ghalandarpoorattar SM, Kaviani A, Asghari F. Medical error disclosure: the gap between attitude and practice. Postgrad Med J 2012;88(1037):130-133.

53. Wu AW, Huang IC, Stokes S, Pronovost PJ. Disclosing medical errors to patients: it's not what you say, it's what they hear. J Gen Intern Med 2009;24(9):1012-1017.

54. Cleopas A, Villaveces A, Charvet A, Bovier PA, Kolly V, Perneger TV. Patient assessments of a hypothetical medical error: effects of health outcome, disclosure, and staff responsiveness. Qual Saf Health Care 2006;15(2):136-141.

55. Mazor KM, Reed GW, Yood RA, Fischer MA, Baril J, Gurwitz JH Disclosure of medical errors: what factors influence how patients respond? J Gen Intern Med 2006;21(7):704-710.

56. López L, Weissman JS, Schneider EC, Weingart SN, Cohen AP, Epstein AM. Disclosure of hospital adverse events and its association with patients' ratings of the quality of care. Arch Intern Med 2009;169(20):1888-1894. 
57. Martinez W, Lo B. Medical students' experiences with medical errors: an analysis of medical student essays. Med Educ 2008; 42(7):733-741.

58. Wagner LM, Harkness K, Hébert PC, Gallagher TH. Nurses' perceptions of error reporting and disclosure in nursing homes. J Nurs Care Qual 2012;27(1):63-69.

59. Sorensen R, ledema R, Piper D, Manias E, Williams A, Tuckett A. Disclosing clinical adverse events to patients: can practice inform policy? Health Expect 2010;13(2):148-159.

60. Sorensen R, ledema R, Piper D, Manias E, Williams A, Tuckett A. Health care professionals' views of implementing a policy of open disclosure of errors. J Health Serv Res Policy 2008;13(4): 227-232.

61. Elwy AR, Bokhour BG, Maguire EM, Wagner TH, Asch SM, Gifford $A L$, et al. Improving healthcare systems' disclosures of large-scale adverse events: a Department of Veterans Affairs leadership, policymaker, research and stakeholder partnership. J Gen Intern Med 2014;29 Suppl 4:895-903.

62. Renkema E, Broekhuis M, Ahaus K. Conditions that influence the impact of malpractice litigation risk on physicians' behavior regarding patient safety. BMC Health Serv Res 2014;14:38.

63. Hobgood C, Weiner B, Tamayo-Sarver JH. Medical error identification, disclosure, and reporting: do emergency medicine provider groups differ? Acad Emerg Med 2006;13(4):443-451.

64. Shannon SE, Foglia MB, Hardy M, Gallagher TH. Disclosing errors to patients: perspectives of registered nurses. Jt Comm J Qual Patient Saf 2009;35(1):5-12.

65. Barrios L, Tsuda S, Derevianko A, Barnett S, Moorman D, Cao $\mathrm{CL}$, et al. Framing family conversation after early diagnosis of iatrogenic injury and incidental findings. Surg Endosc 2009; 23(11):2535-2542.

66. Bonnema RA, Gosman GG, Arnold RM. Teaching error disclosure to residents: a curricular innovation and pilot study. J Grad Med Educ 2009;1(1):114-118.

67. Brown SD, Callahan MJ, Browning DM, Lebowitz RL, Bell SK, Jang J, et al. Radiology trainees' comfort with difficult conversations and attitudes about error disclosure: effect of a communication skills workshop. J Am Coll Radiol 2014;11(8):781787.

68. Etchegaray JM, Gallagher TH, Bell SK, Dunlap B, Thomas EJ. Er- ror disclosure: a new domain for safety culture assessment. BMJ Qual Saf 2012;21(7):594-599.

69. Gunderson AJ, Smith KM, Mayer DB, McDonald T, Centomani N. Teaching medical students the art of medical error full disclosure: evaluation of a new curriculum. Teach Learn Med 2009; 21(3):229-232.

70. Martinez W, Hickson GB, Miller BM, Doukas DJ, Buckley JD, Song J, et al. Role-modeling and medical error disclosure: a national survey of trainees. Acad Med 2014;89(3):482-489.

71. Posner G, Nakajima A. Assessing residents' communication skills: disclosure of an adverse event to a standardized patient. J Obstet Gynaecol Can 2011;33(3):262-268.

72. Raja S, Rajagopalan CF, Patel J, Van Kanegan K. Teaching dental students about patient communication following an adverse event: a pilot educational module. J Dent Educ 2014;78 (5):757-762.

73. Sukalich S, Elliott JO, Ruffner G. Teaching medical error disclosure to residents using patient-centered simulation training. Acad Med 2014;89(1):136-143.

74. Wayman KI, Yaeger KA, Sharek PJ, Trotter S, Wise L, Flora JA, et al. Simulation-based medical error disclosure training for pediatric healthcare professionals. J Healthc Qual 2007;29(4):1219.

75. Coffey M, Thomson K, Tallett S, Matlow A. Pediatric residents' decision-making around disclosing and reporting adverse events: the importance of social context. Acad Med 2010;85 (10):1619-1625.

76. Westbrook JI, Li L, Lehnbom EC, Baysari MT, Braithwaite J, Burke $\mathrm{R}$, et al. What are incident reports telling us? A comparative study at two Australian hospitals of medication errors identified at audit, detected by staff and reported to an incident system. Int J Qual Health Care 2015;27(1):1-9.

77. Hobgood C, Peck CR, Gilbert B, Chappell K, Zou B. Medical errors-what and when: what do patients want to know? Acad Emerg Med 2002;9(11):1156-1161.

78. Saitta N, Hodge SD Jr. Efficacy of a physician's words of empathy: an overview of state apology laws. J Am Osteopath Assoc 2012;112(5):302-306.

79. Leotsakos A, Zheng H, Croteau R, Loeb JM, Sherman H, Hoffman $C$, et al. Standardization in patient safety: the WHO High 5s project. Int J Qual Health Care 2014;26(2):109-116. 


\section{Journal of}

Preventive Medicine \& Public Health

Supplemental Table 1. Search ${ }^{1}$ strategy for the present systematic review

\begin{tabular}{|c|c|c|}
\hline & MeSH term & Other search term \\
\hline Healthcare professionals/the general public & $\begin{array}{l}\text { Professional-Patient } \\
\text { Relations[MeSH] OR } \\
\text { Professional-Family } \\
\text { Relations[MeSH] OR } \\
\text { Patients[MeSH] OR Health } \\
\text { Personnel[MeSH] }\end{array}$ & $\begin{array}{l}\text { Health Care Provider*[TIAB] OR health } \\
\text { person* }{ }^{*} \text { TIAB] OR Healthcare } \\
\text { Provider* }[T I A B] \text { OR Patient* }{ }^{*} \text { TIAB] OR } \\
\text { Physician* }{ }^{*} \text { TIAB] OR nurse* }[\text { TIAB] OR } \\
\text { Fieldworker*[TIAB] }\end{array}$ \\
\hline Error & $\begin{array}{l}\text { Medical Errors[MeSH] OR } \\
\text { Medication Errors[MeSH] OR } \\
\text { Malpractice[MeSH] }\end{array}$ & $\begin{array}{l}\text { Truth[TIAB] OR Adverse event*[TIAB] OR } \\
\text { error[TIAB] OR errors[TIAB] OR } \\
\text { mistak*[TIAB] }\end{array}$ \\
\hline Disclosure & $\begin{array}{l}\text { Disclosure[MeSH] OR } \\
\text { Self Disclosure[MeSH] }\end{array}$ & $\begin{array}{l}\text { Disclosure[TIAB] OR disclose[TIAB] OR } \\
\text { disclosing[TIAB] OR sorry[TIAB] OR } \\
\text { Notification[TIAB] OR apolog*[TIAB] OR } \\
\text { talk[TIAB] OR talks[TIAB] OR talking[TIAB] } \\
\text { OR "duty of candour"[TIAB] }\end{array}$ \\
\hline
\end{tabular}

'Date of search: March 13, 2015. 
Supplemental Table 2. List of articles (99 items) included in the qualitative synthesis

\section{List of article (99 items)}

A01. Adams MA, Elmunzer BJ, Scheiman JM. Effect of a health system's medical error disclosure program on gastroenterology-related claims rates and costs. Am J Gastroenterol 2014;109(4):460-464.

A02. Barrios L, Tsuda S, Derevianko A, Barnett S, Moorman D, Cao CL, et al. Framing family conversation after early diagnosis of iatrogenic injury and incidental findings. Surg Endosc 2009;23(11):2535-2542.

A03. Belela AS, Peterlini MA, Pedreira Mda L. Disclosure of medication error in a pediatric intensive care unit. Rev Bras Ter Intensiva 2010;22(3):257-263.

A04. Bell SK, Moorman DW, Delbanco T. Improving the patient, family, and clinician experience after harmful events: the "when things go wrong" curriculum. Acad Med 2010;85(6):1010-1017.

A05. Bonnema RA, Gosman GG, Arnold RM. Teaching error disclosure to residents: a curricular innovation and pilot study. J Grad Med Educ 2009;1(1):114-118.

A06. Brown SD, Callahan MJ, Browning DM, Lebowitz RL, Bell SK, Jang J, et al. Radiology trainees' comfort with difficult conversations and attitudes about error disclosure: effect of a communication skills workshop. J Am Coll Radiol 2014;11(8):781-787.

A07. Chan DK, Gallagher TH, Reznick R, Levinson W. How surgeons disclose medical errors to patients: a study using standardized patients. Surgery 2005;138(5):851-858.

A08. Cleopas A, Villaveces A, Charvet A, Bovier PA, Kolly V, Perneger TV. Patient assessments of a hypothetical medical error: effects of health outcome, disclosure, and staff responsiveness. Qual Saf Health Care 2006;15(2):136-141.

A09. Coffey M, Thomson K, Tallett S, Matlow A. Pediatric residents' decision-making around disclosing and reporting adverse events: the importance of social context. Acad Med 2010;85(10):1619-1625.

A10. Cole AP, Block L, Wu AW. On higher ground: ethical reasoning and its relationship with error disclosure. BMJ Qual Saf 2013;22(7):580-585.

A11. Dietz I, Borasio GD, Molnar C, Müller-Busch C, Plog A, Schneider G, et al. Errors in palliative care: kinds, causes, and consequences: a pilot survey of experiences and attitudes of palliative care professionals. J Palliat Med 2013;16(1):74-81.

A12. Dintzis SM, Stetsenko GY, Sitlani CM, Gronowski AM, Astion ML, Gallagher TH. Communicating pathology and laboratory errors: anatomic pathologists' and laboratory medical directors' attitudes and experiences. Am J Clin Pathol 2011;135(5):760-765.

A13. Duffy A. An analysis of the culture in Ireland on open disclosure following adverse events in healthcare. Clin Risk 2012;18(6):217-223.

A14. Elwy AR, Bokhour BG, Maguire EM, Wagner TH, Asch SM, Gifford AL, et al. Improving healthcare systems' disclosures of large-scale adverse events: a Department of Veterans Affairs leadership, policymaker, research and stakeholder partnership. J Gen Intern Med 2014;29 Suppl 4:895-903.

A15. Espin S, Levinson W, Regehr G, Baker GR, Lingard L. Error or "act of God"? A study of patients' and operating room team members' perceptions of error definition, reporting, and disclosure. Surgery 2006;139(1):6-14.

A16. Etchegaray JM, Gallagher TH, Bell SK, Dunlap B, Thomas EJ. Error disclosure: a new domain for safety culture assessment. BMJ Qual Saf 2012;21(7):594-599.

A17. Evans SB, Yu JB, Chagpar A. How radiation oncologists would disclose errors: results of a survey of radiation oncologists and trainees. Int J Radiat Oncol Biol Phys 2012;84(2):e131-e137.

A18. Fisseni G, Pentzek M, Abholz HH. Responding to serious medical error in general practice--consequences for the GPs involved: analysis of 75 cases from Germany. Fam Pract 2008;25(1):9-13.

A19. Flotta D, Rizza P, Bianco A, Pileggi C, Pavia M. Patient safety and medical errors: knowledge, attitudes and behavior among Italian hospital physicians. Int J Qual Health Care 2012;24(3):258-265.

A20. Gallagher TH, Waterman AD, Ebers AG, Fraser VJ, Levinson W. Patients' and physicians' attitudes regarding the disclosure of medical errors. JAMA 2003;289(8): 1001-1007.

A21. Gallagher TH, Garbutt JM, Waterman AD, Flum DR, Larson EB, Waterman BM, et al. Choosing your words carefully: how physicians would disclose harmful medical errors to patients. Arch Intern Med 2006;166(15):1585-1593.

A22. Gallagher TH, Waterman AD, Garbutt JM, Kapp JM, Chan DK, Dunagan WC, et al. US and Canadian physicians' attitudes and experiences regarding disclosing errors to patients. Arch Intern Med 2006;166(15):1605-1611.

A23. Gallagher TH, Cook AJ, Brenner RJ, Carney PA, Miglioretti DL, Geller BM, et al. Disclosing harmful mammography errors to patients. Radiology 2009;253(2):443-452.

A24. Garbutt J, Brownstein DR, Klein EJ, Waterman A, Krauss MJ, Marcuse EK, et al. Reporting and disclosing medical errors: pediatricians' attitudes and behaviors. Arch Pediatr Adolesc Med 2007;161(2):179-185.

A25. Ghalandarpoorattar SM, Kaviani A, Asghari F. Medical error disclosure: the gap between attitude and practice. Postgrad Med J 2012;88(1037):130-133.

A26. Gu X, Itoh K. Patient views and attitudes to physician's actions after medical errors in China. J Patient Saf 2012;8(4):153-160.

A27. Gunderson AJ, Smith KM, Mayer DB, McDonald T, Centomani N. Teaching medical students the art of medical error full disclosure: evaluation of a new curriculum. Teach Learn Med 2009;21(3):229-232.

A28. Hammami MM, Attalah S, Al Qadire M. Which medical error to disclose to patients and by whom? Public preference and perceptions of norm and current practice. BMC Med Ethics 2010;11:17.

A29. Hannawa AF. "Explicitly implicit": examining the importance of physician nonverbal involvement during error disclosures. Swiss Med Wkly 2012;142:w13576.

A30. Hannawa AF. Disclosing medical errors to patients: effects of nonverbal involvement. Patient Educ Couns 2014;94(3):310-313.

A31. Hayes B. Medical errors - a hospital in Nepal searches for answers. Trop Doct 2008;38(1):45-48.

A32. Helmchen LA, Richards MR, McDonald TB. How does routine disclosure of medical error affect patients' propensity to sue and their assessment of provider quality? Evidence from survey data. Med Care 2010;48(11):955-961. 


\section{Supplemental Table 2. Continued from the previous page}

\section{List of article (99 items)}

A33. Hingorani M, Wong T, Vafidis G. Attitudes after unintended injury during treatment a survey of doctors and patients. West J Med 1999;171(2):81-82.

A34. Hobgood C, Peck CR, Gilbert B, Chappell K, Zou B. Medical errors-what and when: what do patients want to know? Acad Emerg Med 2002;9(11):1156-1161.

A35. Hobgood C, Xie J, Weiner B, Hooker J. Error identification, disclosure, and reporting: practice patterns of three emergency medicine provider types. Acad Emerg Med 2004;11(2):196-199.

A36. Hobgood C, Tamayo-Sarver JH, Elms A, Weiner B. Parental preferences for error disclosure, reporting, and legal action after medical error in the care of their children. Pediatrics 2005;116(6):1276-1286.

A37. Hobgood C, Hevia A, Tamayo-Sarver JH, Weiner B, Riviello R. The influence of the causes and contexts of medical errors on emergency medicine residents' responses to their errors: an exploration. Acad Med 2005;80(8):758-764.

A38. Hobgood C, Bowen JB, Brice JH, Overby B, Tamayo-Sarver JH. Do EMS personnel identify, report, and disclose medical errors? Prehosp Emerg Care 2006;10(1):21-27.

A39. Hobgood C, Weiner B, Tamayo-Sarver JH. Medical error identification, disclosure, and reporting: do emergency medicine provider groups differ? Acad Emerg Med 2006;13(4):443-451.

A40. Hobgood C, Tamayo-Sarver JH, Weiner B. Patient race/ethnicity, age, gender and education are not related to preference for or response to disclosure. Qual Saf Health Care 2008;17(1):65-70.

A41. ledema R, Sorensen R, Manias E, Tuckett A, Piper D, Mallock N, et al. Patients' and family members' experiences of open disclosure following adverse events. Int J Qual Health Care 2008;20(6):421-432.

A42. ledema R, Allen S, Britton K, Piper D, Baker A, Grbich C, et al. Patients' and family members' views on how clinicians enact and how they should enact incident disclosure: the "100 patient stories" qualitative study. BMJ 2011;343:d4423.

A43. ledema R, Allen S, Sorensen R, Gallagher TH. What prevents incident disclosure, and what can be done to promote it? Jt Comm J Qual Patient Saf 2011;37(9):409-417.

A44. ledema RA, Mallock NA, Sorensen RJ, Manias E, Tuckett AG, Williams AF, et al. The National Open Disclosure Pilot: evaluation of a policy implementation initiative. Med J Aust 2008;188(7):397-400.

A45. ledema R, Jorm C, Wakefield J, Ryan C, Sorensen R. A new structure of attention? Open disclosure of adverse events to patients and their families. J Lang Soc Psychol 2009;28(2):139-157.

A46. lezzoni LI, Rao SR, DesRoches CM, Vogeli C, Campbell EG. Survey shows that at least some physicians are not always open or honest with patients. Health Aff (Millwood) 2012;31(2):383-391.

A47. Kachalia A, Kaufman SR, Boothman R, Anderson S, Welch K, Saint S, et al. Liability claims and costs before and after implementation of a medical error disclosure program. Ann Intern Med 2010;153(4):213-221.

A48. Kaldjian LC, Jones EW, Wu BJ, Forman-Hoffman VL, Levi BH, Rosenthal GE. Disclosing medical errors to patients: attitudes and practices of physicians and trainees. J Gen Intern Med 2007;22(7):988-996.

A49. Knifed E, Goyal A, Bernstein M. Moral angst for surgical residents: a qualitative study. Am J Surg. 2010 Apr;199(4):571-576.

A50. Kooienga S, Stewart VT. Putting a face on medical errors: a patient perspective. J Healthc Qual 2011;33(4):37-41.

A51. Kronman AC, Paasche-Orlow M, Orlander JD. Factors associated with disclosure of medical errors by housestaff. BMJ Qual Saf 2012;21(4):271-278.

A52. Lander LI, Connor JA, Shah RK, Kentala E, Healy GB, Roberson DW. Otolaryngologists' responses to errors and adverse events. Laryngoscope 2006;116(7):1114-1120.

A53. Lehmann LS, Puopolo AL, Shaykevich S, Brennan TA. latrogenic events resulting in intensive care admission: frequency, cause, and disclosure to patients and institutions. Am J Med 2005;118(4):409-413.

A54. Lester GW, Smith SG. Listening and talking to patients. A remedy for malpractice suits? West J Med 1993;158(3):268-272.

A55. Liao JM, Etchegaray JM, Williams ST, Berger DH, Bell SK, Thomas EJ. Assessing medical students' perceptions of patient safety: the medical student safety attitudes and professionalism survey. Acad Med 2014;89(2):343-351.

A56. López L, Weissman JS, Schneider EC, Weingart SN, Cohen AP, Epstein AM. Disclosure of hospital adverse events and its association with patients' ratings of the quality of care. Arch Intern Med 2009;169(20):1888-1894.

A57. Loren DJ, Klein EJ, Garbutt J, Krauss MJ, Fraser V, Dunagan WC, et al. Medical error disclosure among pediatricians: choosing carefully what we might say to parents Arch Pediatr Adolesc Med 2008;162(10):922-927.

A58. Loren DJ, Garbutt J, Dunagan WC, Bommarito KM, Ebers AG, Levinson W, et al. Risk managers, physicians, and disclosure of harmful medical errors. Jt Comm J Qual Patient Saf 2010;36(3):101-108.

A59. Luk LA, Ng WI, Ko KK, Ung VH. Nursing management of medication errors. Nurs Ethics 2008;15(1):28-39.

A60. Lyu HG, Cooper MA, Mayer-Blackwell B, Jiam N, Hechenbleikner EM, Wick EC, et al. Medical harm: patient perceptions and follow-up actions. J Patient Saf 2014. doi: https://doi.org/ 10.1097/PTS.0000000000000136.

A61. Martinez W, Lo B. Medical students' experiences with medical errors: an analysis of medical student essays. Med Educ 2008;42(7):733-741.

A62. Martinez W, Hickson GB, Miller BM, Doukas DJ, Buckley JD, Song J, et al. Role-modeling and medical error disclosure: a national survey of trainees. Acad Med 2014;89(3):482-489.

A63. Matlow AG, Moody L, Laxer R, Stevens P, Goia C, Friedman JN. Disclosure of medical error to parents and paediatric patients: assessment of parents' attitudes and influencing factors. Arch Dis Child 2010;95(4):286-290.

A64. May N, Plews-Ogan M. The role of talking (and keeping silent) in physician coping with medical error: a qualitative study. Patient Educ Couns 2012;88(3):449-454.

(Continued to the next page) 


\section{List of article (99 items)}

A65. Mazor KM, Simon SR, Yood RA, Martinson BC, Gunter MJ, Reed GW, et al. Health plan members' views about disclosure of medical errors. Ann Intern Med 2004;140(6):409-418.

A66. Mazor KM, Reed GW, Yood RA, Fischer MA, Baril J, Gurwitz JH. Disclosure of medical errors: what factors influence how patients respond? J Gen Intern Med 2006;21(7):704-710.

A67. Mazor KM, Goff SL, Dodd KS, Velten SJ, Walsh KE. Parents' perceptions of medical errors. J Patient Saf 2010;6(2):102-107.

A68. Mazor KM, Greene SM, Roblin D, Lemay CA, Firneno CL, Calvi J, et al. More than words: patients' views on apology and disclosure when things go wrong in cancer care. Patient Educ Couns 2013;90(3):341-346.

A69. McLennan S, Engel S, Ruhe K, Leu A, Schwappach D, Elger B. Implementation status of error disclosure standards reported by Swiss hospitals. Swiss Med Wkly 2013;143:w13820.

A70. McLennan SR, Diebold M, Rich LE, Elger BS. Nurses' perspectives regarding the disclosure of errors to patients: A qualitative study. Int J Nurs Stud 2016;54:16-22.

A71. Medau I, Jox RJ, Reiter-Theil S. How psychotherapists handle treatment errors -- an ethical analysis. BMC Med Ethics 2013;14:50.

A72. Nevalainen M, Kuikka L, Pitkälä K. Medical errors and uncertainty in primary healthcare: a comparative study of coping strategies among young and experienced GPs. Scand J Prim Health Care 2014;32(2):84-89.

A73. Northcott H, Vanderheyden L, Northcott J, Adair C, McBrien-Morrison C, Norton P, et al. Perceptions of preventable medical errors in Alberta, Canada. Int J Qual Health Care 2008;20(2):115-122.

A74. Ogundiran T0, Adebamowo CA. Surgeon-patient information disclosure practices in southwestern Nigeria. Med Princ Pract 2012;21(3):238-243.

A75. Piper D, ledema R, Bower K. Rural patients' experiences of the open disclosure of adverse events. Aust J Rural Health 2014;22(4):197-203.

A76. Posner G, Nakajima A. Assessing residents' communication skills: disclosure of an adverse event to a standardized patient. J Obstet Gynaecol Can 2011;33(3):262-268.

A77. Raja S, Rajagopalan CF, Patel J, Van Kanegan K. Teaching dental students about patient communication following an adverse event: a pilot educational module. J Dent Educ 2014;78(5):757-762.

A78. Renkema E, Broekhuis M, Ahaus K. Conditions that influence the impact of malpractice litigation risk on physicians' behavior regarding patient safety. BMC Health Serv Res 2014;14:38.

A79. Rinke ML, Bundy DG, Shore AD, Colantuoni E, Morlock LL, Miller MR. Pediatric antidepressant medication errors in a national error reporting database. J Dev Behav Pediatr 2010;31(2):129-136.

A80. Schwappach DL, Koeck CM. What makes an error unacceptable? A factorial survey on the disclosure of medical errors. Int J Qual Health Care 2004;16(4):317-326.

A81. Shannon SE, Foglia MB, Hardy M, Gallagher TH. Disclosing errors to patients: perspectives of registered nurses. Jt Comm J Qual Patient Saf 2009;35(1):5-12.

A82. Sorensen R, ledema R, Piper D, Manias E, Williams A, Tuckett A. Health care professionals' views of implementing a policy of open disclosure of errors. J Health Serv Res Policy 2008;13(4):227-232.

A83. Sorensen R, ledema R, Piper D, Manias E, Williams A, Tuckett A. Disclosing clinical adverse events to patients: can practice inform policy? Health Expect 2010;13(2):148-159.

A84. Sorokin R, Riggio JM, Hwang C. Attitudes about patient safety: a survey of physicians-in-training. Am J Med Qual 2005;20(2):70-77.

A85. Sorokin R, Riggio JM, Moleski S, Sullivan J. Physicians-in-training attitudes on patient safety: 2003 to 2008. J Patient Saf 2011;7(3):133-138.

A86. Stroud L, Mcllroy J, Levinson W. Skills of internal medicine residents in disclosing medical errors: a study using standardized patients. Acad Med 2009;84(12): 1803-1808.

A87. Sukalich S, Elliott J0, Ruffner G. Teaching medical error disclosure to residents using patient-centered simulation training. Acad Med 2014;89(1):136-143.

A88. Ushie BA, Salami KK, Jegede AS, Oyetunde M. Patients' knowledge and perceived reactions to medical errors in a tertiary health facility in Nigeria. Afr Health Sci 2013;13(3):820-828.

A89. Varjavand N, Bachegowda LS, Gracely E, Novack DH. Changes in intern attitudes toward medical error and disclosure. Med Educ 2012;46(7):668-677.

A90. Vincent CA, Pincus T, Scurr JH. Patients' experience of surgical accidents. Qual Health Care 1993;2(2):77-82.

A91. Vincent JL. Information in the ICU: are we being honest with our patients? The results of a European questionnaire. Intensive Care Med 1998;24(12):1251-1256.

A92. Wagner LM, Harkness K, Hébert PC, Gallagher TH. Nurses' perceptions of error reporting and disclosure in nursing homes. J Nurs Care Qual 2012;27(1):63-69.

A93. Wagner LM, Harkness K, Hébert PC, Gallagher TH. Nurses' disclosure of error scenarios in nursing homes. Nurs Outlook 2013;61(1):43-50.

A94. Wayman KI, Yaeger KA, Sharek PJ, Trotter S, Wise L, Flora JA, et al. Simulation-based medical error disclosure training for pediatric healthcare professionals. J Healthc Qual 2007;29(4):12-19.

A95. White AA, Gallagher TH, Krauss MJ, Garbutt J, Waterman AD, Dunagan WC, et al. The attitudes and experiences of trainees regarding disclosing medical errors to patients. Acad Med 2008;83(3):250-256.

A96. White AA, Bell SK, Krauss MJ, Garbutt J, Dunagan WC, Fraser VJ, et al. How trainees would disclose medical errors: educational implications for training programmes. Med Educ 2011;45(4):372-380.

A97. Witman AB, Park DM, Hardin SB. How do patients want physicians to handle mistakes? A survey of internal medicine patients in an academic setting. Arch Intern Med 1996; 156(22):2565-2569.

A98. Wu AW, Huang IC, Stokes S, Pronovost PJ. Disclosing medical errors to patients: it's not what you say, it's what they hear. J Gen Intern Med 2009;24(9):1012-1017.

A99. Zhang Q, Li Y, Li J, Mao X, Zhang L, Ying Q, et al. Patients for patient safety in China: a cross sectional study. J Evid Based Med 2012;5(1):6-11. 